\title{
A STUDY ON RELATIONSHIP RECOGNITION AND ANALYSIS THROUGH IOT-BASED INFANT ACTIVITY MONITORING
}

\author{
Hyoung-Keun Park ${ }^{1 *}$ \\ ${ }^{1}$ Dept. of Electronic Engineering, Namseoul University, \\ 91 Daehak-ro Seonghwan-eup Sebuk-gu Cheonan-si, Chungnam-do, South Korea \\ ${ }^{1}$ phk315@nsu.ac.kr
}

\begin{abstract}
In this paper, I have developed a real - time monitoring system that can identify the individual position of infants and their proximity to other infants using the IoT technology - based nameplate. In this way, information about how many infants interact with each infant is identified. The information gathered through this system was used as important information to improve the peer relations of all infants and toddlers, from neglected or rejected infants to infants who had no problems in terms of social development and even more popular infants. Based on proximity information between infants and toddlers, the teacher can identify the type of interaction (positive interaction, negative interaction) and try to improve the relationship of infants and young children and use the results in consultation with parents. Therefore, the data collected through this system is converted into a database to establish a system for improvement of peer relations.
\end{abstract}

Keywords - Real-time monitoring system, Infants interact, Parent consultation, Relationship recognition

\section{INTRODUCTION}

Infant and childhood is the period of development from the perspective of individual life, and it is a time of rapid development and a source of all growth. In the case of social development, infants who have formed a positive social relationship with their peers can have pro-social characteristics in future life, and on the contrary, there is a high possibility that rejected experiences from friends will have negative social characteristics. However, it is not easy to establish a desirable peer relationship for infants. Recently, the tendency to lower the aging of bullying phenomena and the spread of smart devices to younger ages have increased the number of infants who are struggling to properly form social relations with their peers have. Therefore, there is an increasing interest in infants' desirable peer relations [1].

Peer relations have a very important influence on the development of children's sociality and also have a great influence on all developmental areas. Therefore, social position is considered as an important factor in peer relations every week, and various researches have been carried out on various factors influencing the behavior characteristics of popular or non - inhabitants.

For example, research on the relationship between age and infant interaction, the relationship between childhood peer popularity level and social knowledge, social cognitive ability, prosocial behavior and language expression ability, infant popularity and interpersonal problem solving And the effects of parental parenting attitudes on

Received: June 3, 2019

Reviewed: August 14, 2019

Accepted: September 4, 2019 
children's peer acceptance are some of the variables that affect peer relationships. Sadly, unfamiliar infants tend to be ignored and found to be very difficult to accept as friends. In the case of non-trafficked babies, they will receive negative feedback from the moment they enter the play situation, and if such experiences accumulate, they will not be able to rule out the possibility of a friend becoming a child without one [1]-[3].

In order to prevent such unhappiness, it is necessary to understand what kind of behaviors can be accommodated from peers, and it is necessary to seek various intervention methods to improve peer relations. But the first thing to do is to figure out which children in the class are not popular and are rejected or rejected.

Therefore, in this paper, I use a name tag based on IoT technology to collect basic data on the peer relationships of all infants and young children. Monitoring system was constructed.

\section{PEER RELATIONSHIP EVALUATION METHOD}

\subsection{PROBLEMS OF EXISTING PEER RELATIONSHIP EVALUATION METHOD}

In order to improve the peer relations of infants and to provide a cornerstone of desirable social development, it is necessary to evaluate peer relations by using scientific and objective methods.

It has traditionally used peer nomenclature and peer review to measure the social status of peers in infants and toddlers. However, these two methods have disadvantages in that the degree of popularity is regarded as an individual attribute of each infant. Since the peer relationships of infants and toddlers are often determined by their personal characteristics (e.g., the general characteristics of (non) popular sons), they are often determined by the relationship with the whole family and the culture within the group, It is difficult to make an accurate judgment about the peer relations of infants and young children. In addition, peer relations data collected based on teacher's partial observation or intuitive judgment have limitations that are not scientific and objective [4]-[7].

\subsection{NEED FOR A NEW METHOD TO IMPROVE RELATIONS BETWEEN INFANTS AND TODDLERS}

In order to improve the peer relations of infants and toddlers, it is necessary to establish an objective peer relationship evaluation method and to suggest ways to improve peer relations based on the results.

Evaluation by peer nomination and peer evaluation is likely to be based on personal characteristics, and teacher peer relationship evaluation is likely to be fragmentary and prejudiced. Therefore, it is necessary to acquire empirical and specific data on peer relationships, not traditional assessment methods. If I can have empirical data on how infants and young children have actually interacted (or reduced) with a child, I can provide appropriate guidance for improving peer relationships. In the system developed in this paper, I can grasp the individual position of each infant and the degree of maintaining close range with other peers, and constructed a system to monitor it in real time.

Based on the collected information on the interaction between infants and toddlers, it is possible to identify infants who are neglected or rejected, infants who do not have problems in social development, and infants who are more popular. In addition, it can be used as important information to improve the peer relations of infants and toddlers. Although it may not be necessary to improve peer relationships that are popular, there are many cases in which even the most popular infants have many problems in social development. Therefore, the data collected through this system, and the suggestions for improving the relationship between infants and young children using the data, would be 
useful and effective support for all infants and young children, not for some special infants who seem to have problems in social development [1],[8]-[10].

\subsection{LIMITATIONS OF EXISTING TECHNOLOGY AND POSSIBILITY OF IOT TECHNOLOGY}

CCTV has a variety of problems and limitations such as privacy violation, limited realtime information provision, and blind spot generation. On the other hand, the real-time observation technology using IoT technology can observe and record the behaviors, movements, and positions of infants and young children to actively cope with the problem situation, thereby preventing an accident that may occur in the peer relationship. It provides monitoring services through mobile apps to infants educational institutions and households, enabling continuous observation in real time. The analysis engine developed in this study performs the function of providing location information of infants and to provide individual absolute location information of each infant. In addition, it provides relative position information about the degree of proximity to other infants, so that the degree of interaction with peers can be grasped [1], [13]-[17].

\section{RESEARCH AND ANALYSIS OF DATA}

\subsection{COLLECTING DATA}

Only public kindergartens gathered data for 5 - year - old infants at the time of free choice activity, and carried out after obtaining parental consent regarding the conduct of research beforehand. The data were collected 17 times because of various events of kindergarten and class (ecological experience, walking activity, opening day, manners education, traditional play).

However, 14 cases were collected only for some infants because of the initial malfunction of the location tracking device and IoT's recognition defect among 17 collected data. The purpose of this study is to identify what kind of peer relationships an individual child has in the whole structure of the class, and to suggest ways of educating each individual child based on the results. I have. Therefore, I excluded 14 data which could not collect the whole infant's location data from the analysis. All paragraphs must be indented.

\subsection{ANALYSIS DATA}

The data used in this study are location information data using IoT technology. IoT technology is used to database the signals sent by infants to calculate the duration when individual infants are located at close distances. Based on the proxemics proposed by Edward Hall, the duration was calculated only when the proximity distance between children was less than $76[\mathrm{~cm}]$.

The distance of $76[\mathrm{~cm}]$ or less is equivalent to Hall proposed by "Personal distance for interactions among good friends or family". As a result of observation of play distance of children in free choice activity time, it was judged that the distance of interaction is less than $76[\mathrm{~cm}]$.

\subsection{ANALYSIS METHOD}

In this paper, I use SPSS, a standard statistical software program, to calculate the number of hours that individual infants are located close to other infants. Also, I used NetMiner, a software that can execute semantic network analysis and relational data visualization, to draw the social network of the whole class and to calculate the Eigenvectors' central indicators of individual infants. In addition, Multidimensional 
Scaling analysis was performed using SPSS and NetMiner, and Quadratic Assignment Procedure (QAP) analysis was performed using NetMiner.

\section{RESULTS ANALYSIS}

\subsection{PROXIMITY OF INDIVIDUAL INFANTS TO OTHER INFANTS}

The degree of proximity of the infant to other infants is shown in Figure 1 as in Figure 26 , and the Y axis unit of the graph is 'Seconds'.

For example, in the case of the 21 st infant, the time to maintain the close distance with the peer relative to the other infants was not long, and the infant with the 12th infant had a long time to maintain close distance with a specific infant. Also, it was found that the seventeenth infant was kept close to a certain distance, not limited to a specific infant.

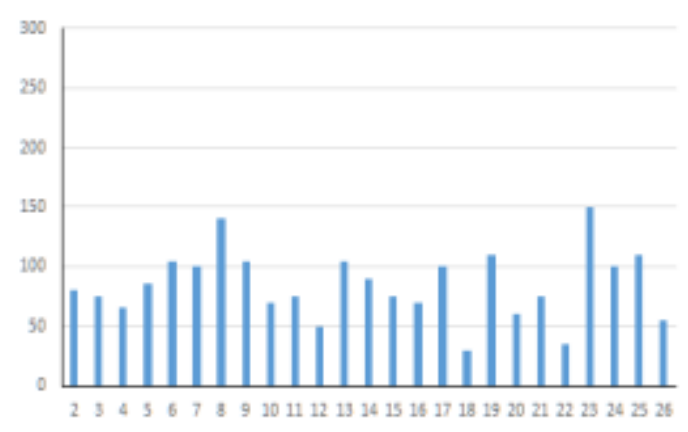

Fig. 1 Proximity of child 1 and others

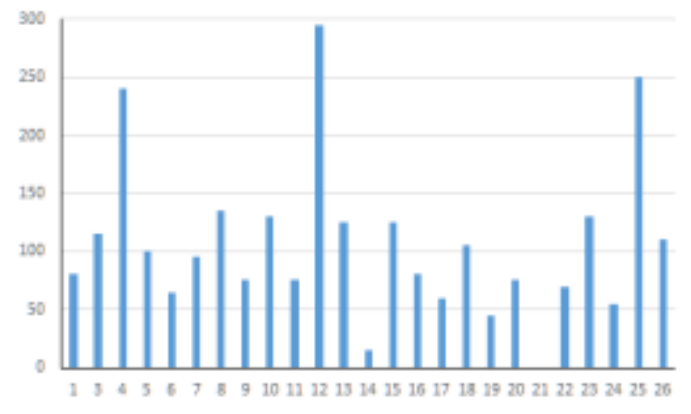

Fig. 3 Proximity of child 3 and others

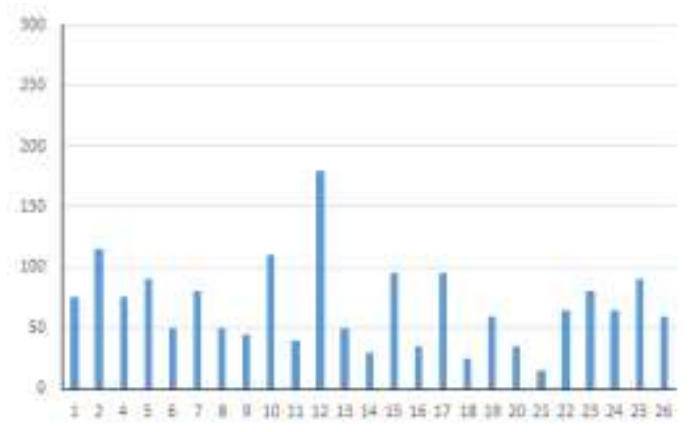

Fig. 2 Proximity of child 2 and others

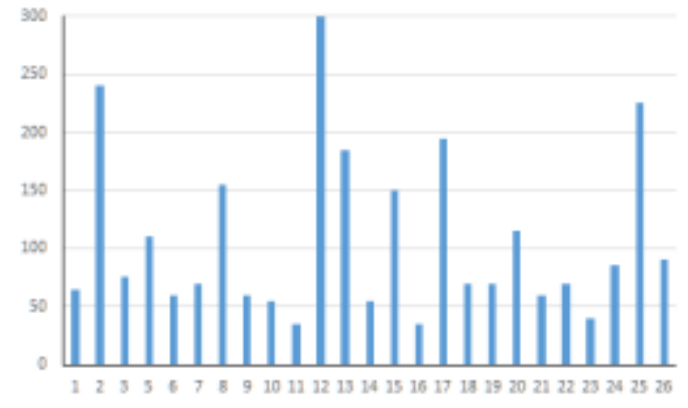

Fig. 4 Proximity of child 4 and others

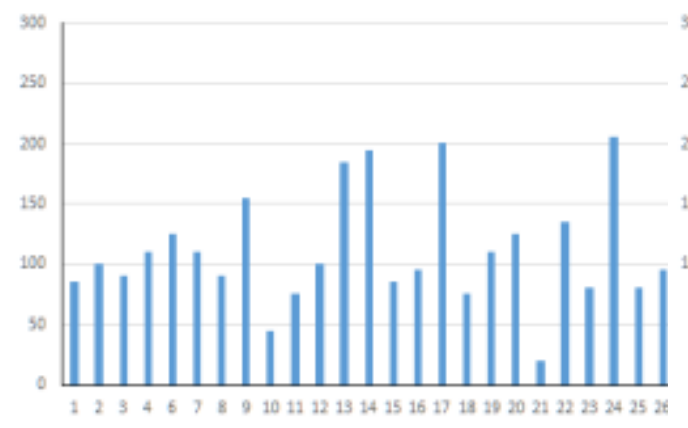

Fig. 5 Proximity of child 5 and others

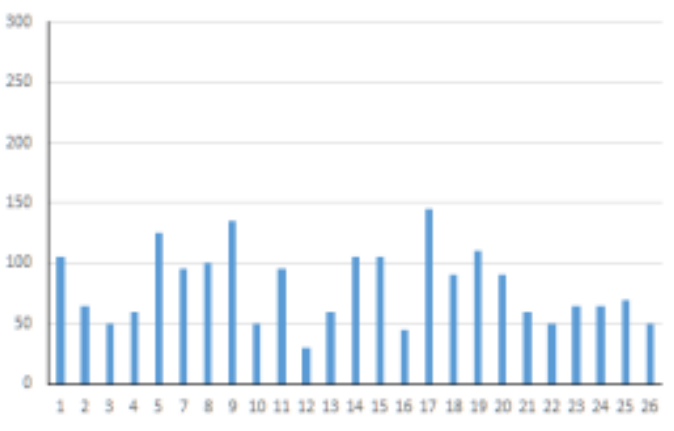

Fig. 6 Proximity of child 6 and others 


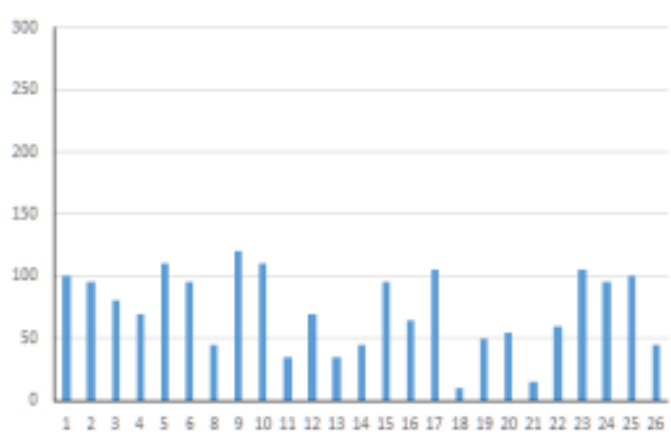

Fig. 7 Proximity of child 7 and others

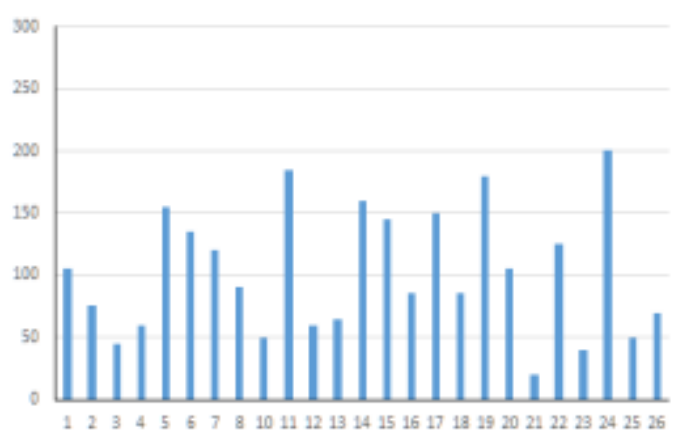

Fig. 9 Proximity of child 9 and others

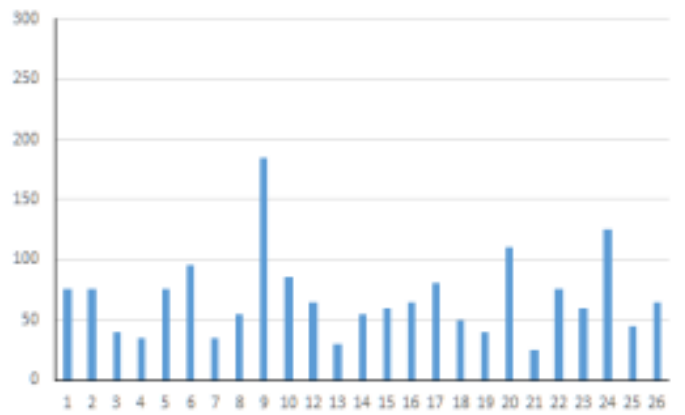

Fig. 11 Proximity of child 11 and others

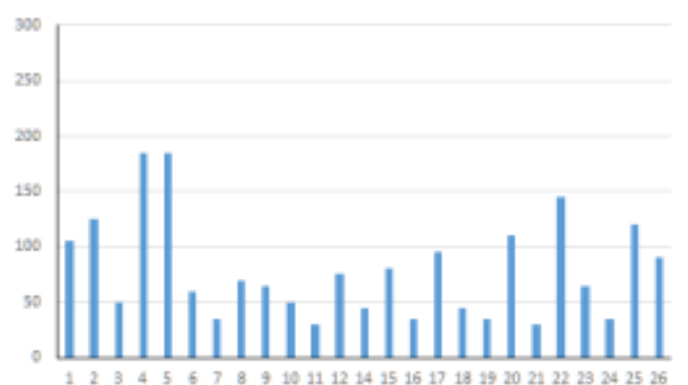

Fig. 13 Proximity of child 11 and others

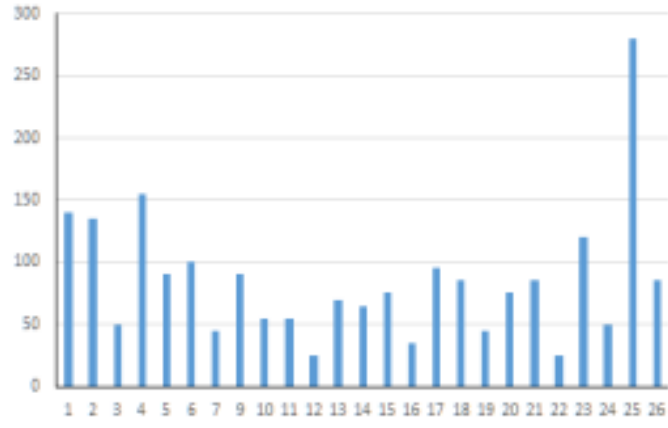

Fig. 8 Proximity of child 8 and others

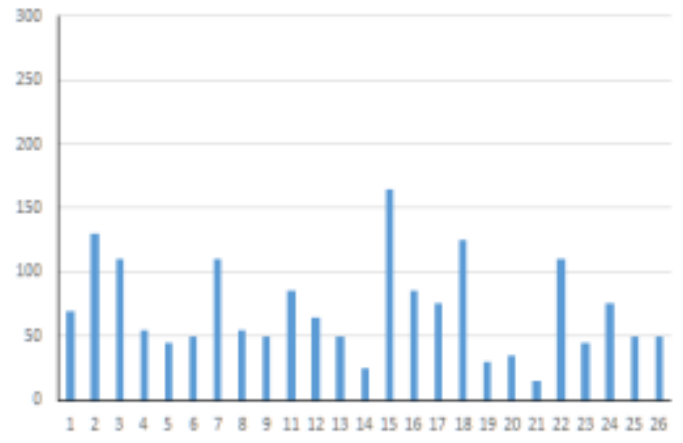

Fig. 10 Proximity of child 10 and others

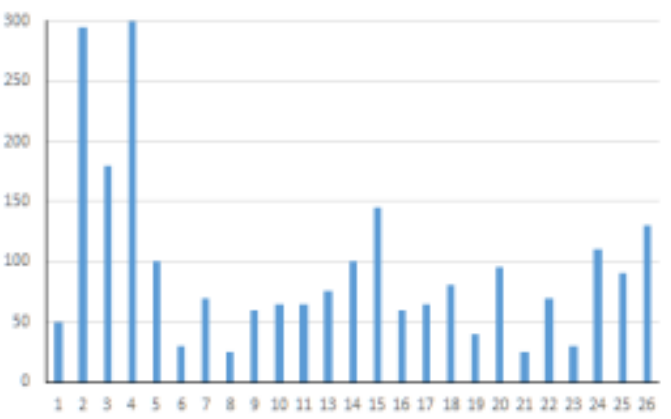

Fig. 12 Proximity of child 12 and others

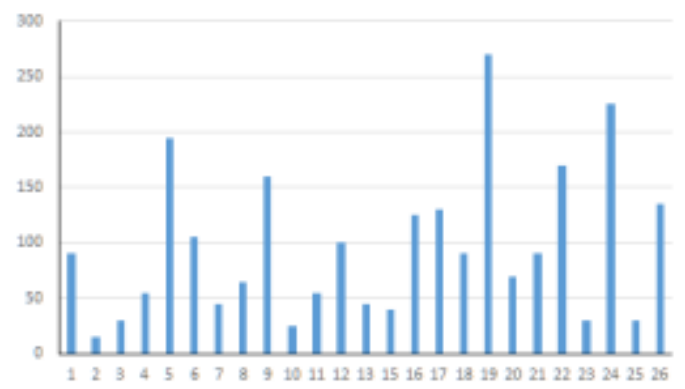

Fig. 14 Proximity of child 12 and others 


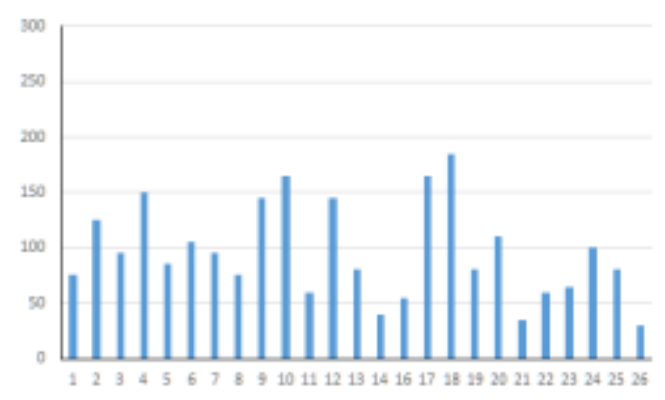

Fig. 15 Proximity of child 15 and others

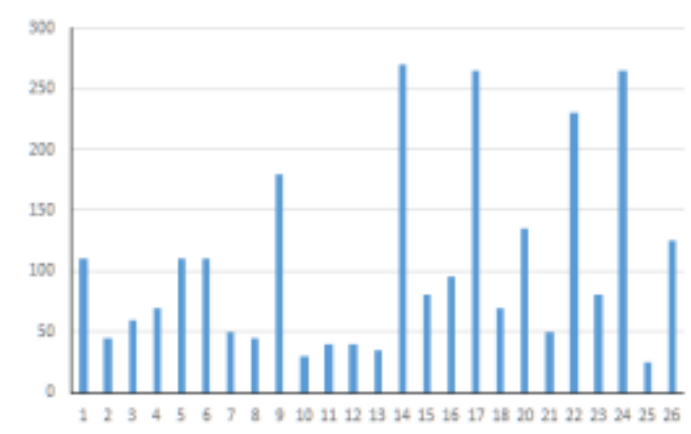

Fig. 17 Proximity of child 17 and others

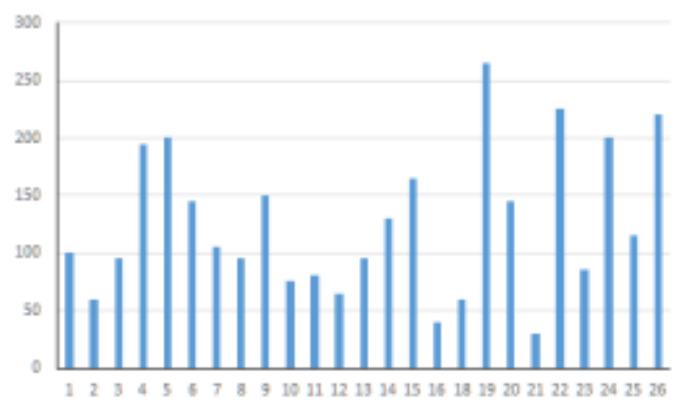

Fig. 19 Proximity of child 19 and others

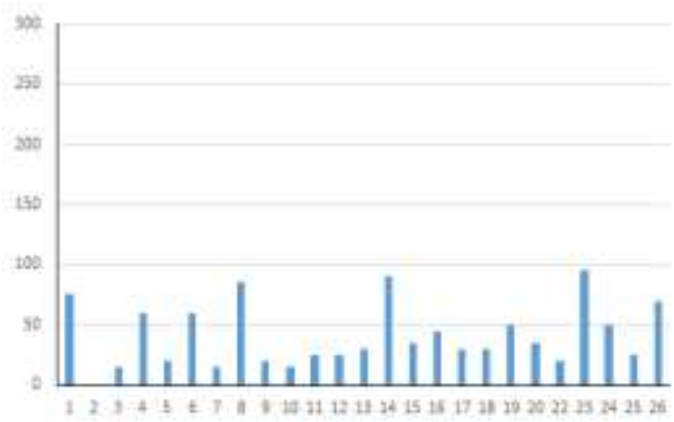

Fig. 21 Proximity of child 21 and others

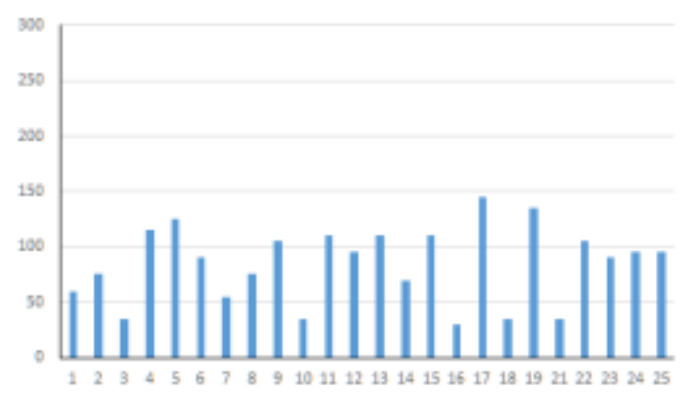

Fig. 16 Proximity of child 16 and others

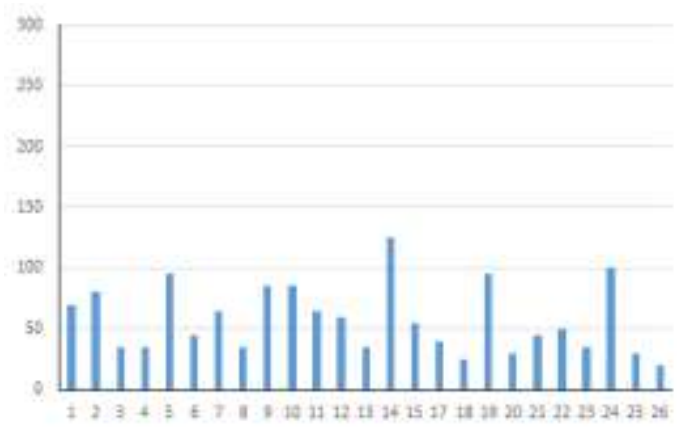

Fig. 18 Proximity of child 18 and others

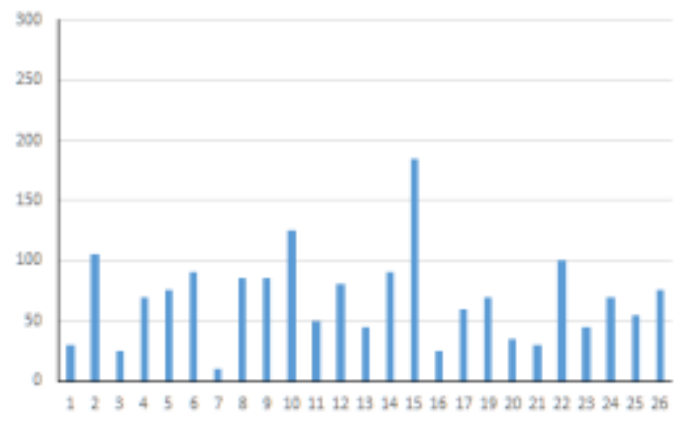

Fig. 20 Proximity of child 20 and others

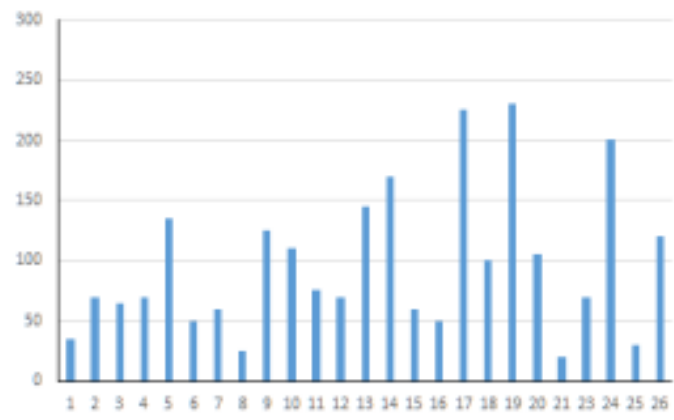

Fig. 22 Proximity of child 22 and others 


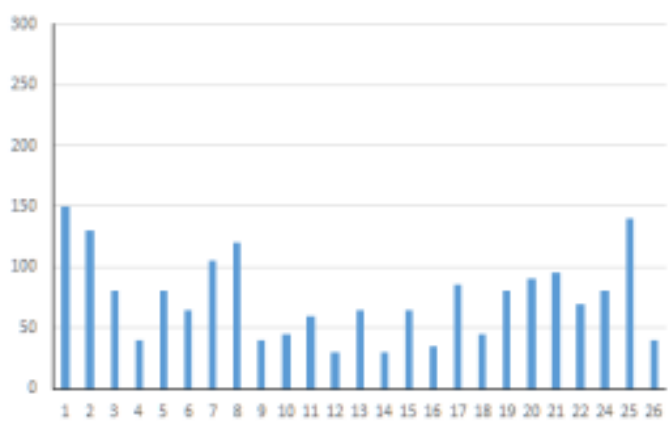

Fig. 23 Proximity of child 23 and others

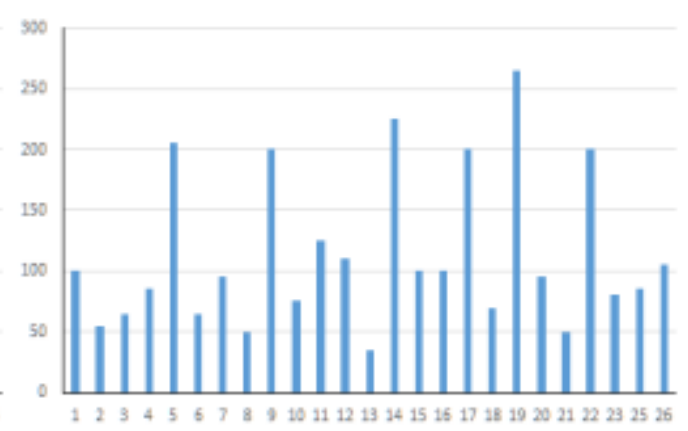

Fig. 24 Proximity of child 24 and others

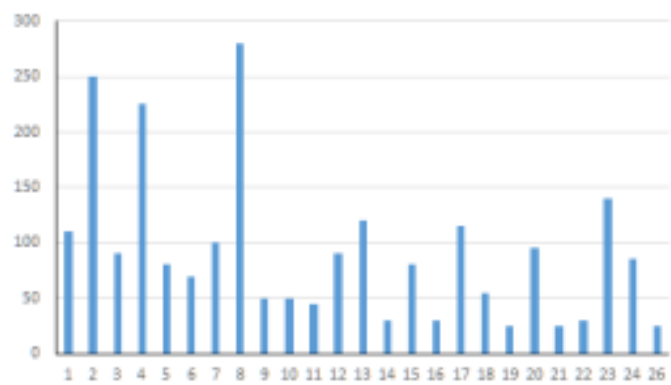

Fig. 25 Proximity of child 25 and others

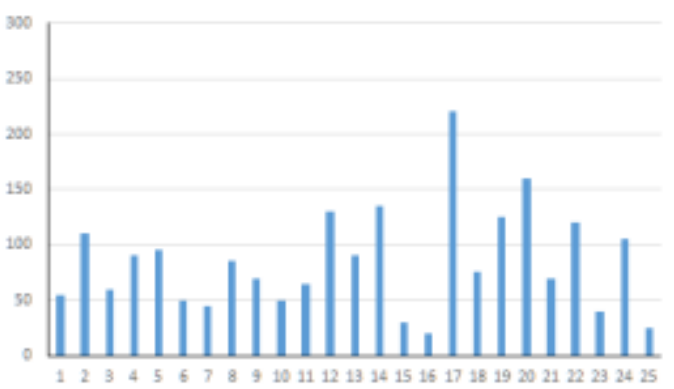

Fig. 26 Proximity of child 26 and others

\subsection{SOCIAL NETWORK STRUCTURE OF WHOLE CLASS}

The results of drawing the social network structure of the whole class using NetMiner are shown in Figure 27 and Figure 28.

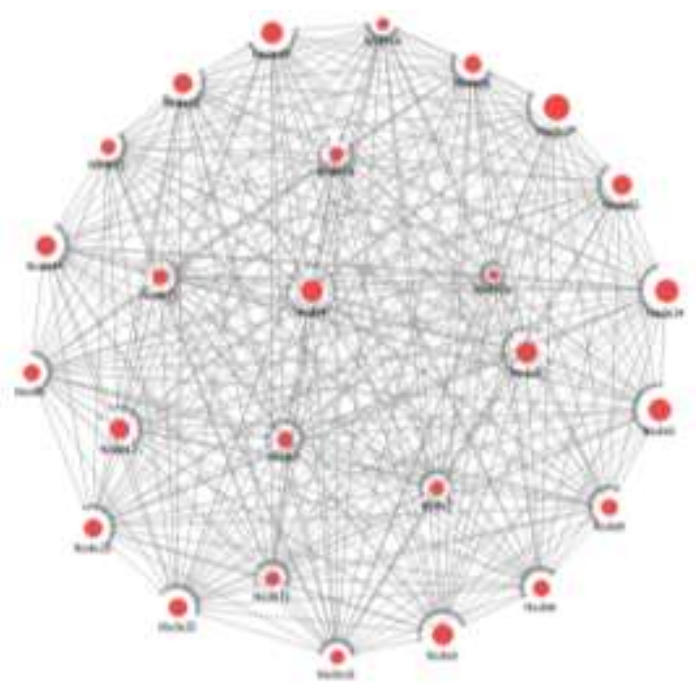

Fig. 27 Social network structure of the whole 5th grade class (spring) 


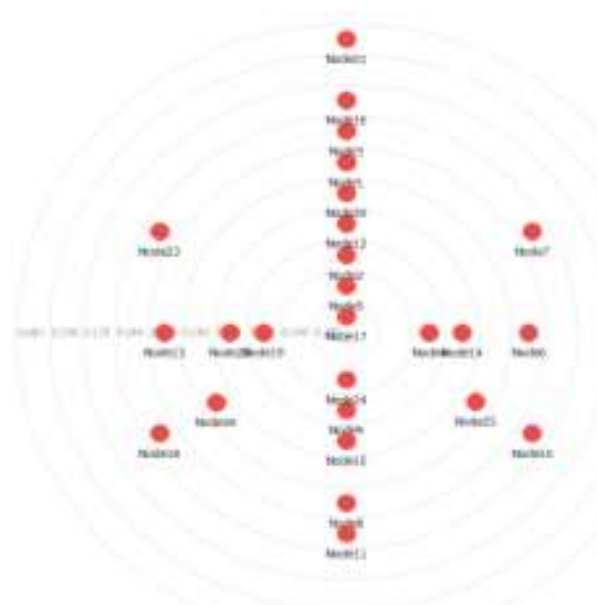

Fig. 28 Social network structure of the whole 5th grade class (concentric)

\subsection{EISEN VECTOR CENTRAL INDICATOR}

Table I shows the result of calculating the Eigenvectors' central indicators of individual infants using NetMiner and aligning them in order of the central indicators. As shown in Table I, the Eisen vector central score was higher in 17th, 24th and 5th order, whereas the central score of 21 th child was the lowest.

Table I. Eisen Vector Central Indicator

\begin{tabular}{c|c|c|c}
\hline Infant ID & Eisen vector central indicator & Infant ID & Eisen vector central indicator \\
\hline 17 & 0.278346 & 26 & 0.188178 \\
\hline 24 & 0.253001 & 8 & 0.182223 \\
\hline 5 & 0.244621 & 1 & 0.179347 \\
\hline 19 & 0.238279 & 6 & 0.176286 \\
\hline 4 & 0.235635 & 13 & 0.172847 \\
\hline 9 & 0.225897 & 7 & 0.159445 \\
\hline 2 & 0.224656 & 23 & 0.158065 \\
\hline 22 & 0.219243 & 18 & 0.151639 \\
\hline 14 & 0.214233 & 3 & 0.150979 \\
\hline 12 & 0.208113 & 11 & 0.150257 \\
\hline 15 & 0.207541 & 10 & 0.149155 \\
\hline 25 & 0.199787 & 16 & 0.126808 \\
\hline 20 & 0.195509 & 21 & 0.086907 \\
\hline
\end{tabular}

\subsection{MULTIDIMENSIONAL SCALING ANALYSIS}

The results of multidimensional scaling analysis using SPSS and NetMiner are shown in Figure 29 and Figure 30. The visual representation of the analysis results was based on the two-dimensional space. The results of the SPSS and NetMiner analyzes are somewhat different, but overall they are similar. To understand the results of the multidimensional scaling analysis, it is necessary to refer to the results of Figure 26 and Table I in Figure 1. 


\section{Euclidean distance model}

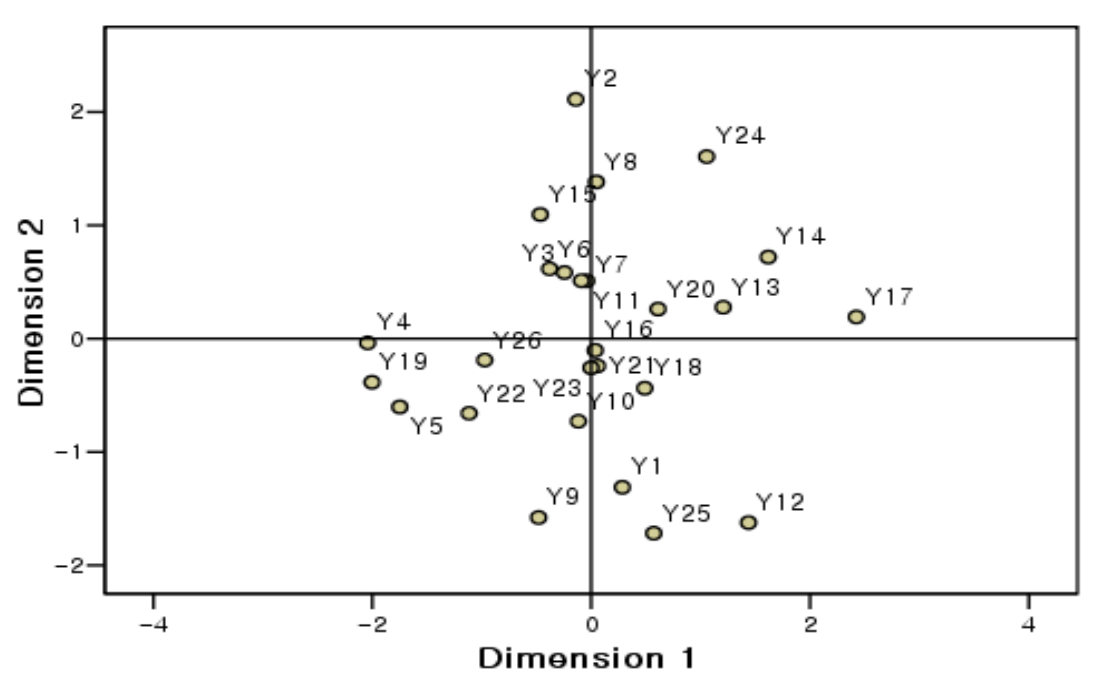

Fig. 29 Multidimensional scaling analysis results obtained by SPSS

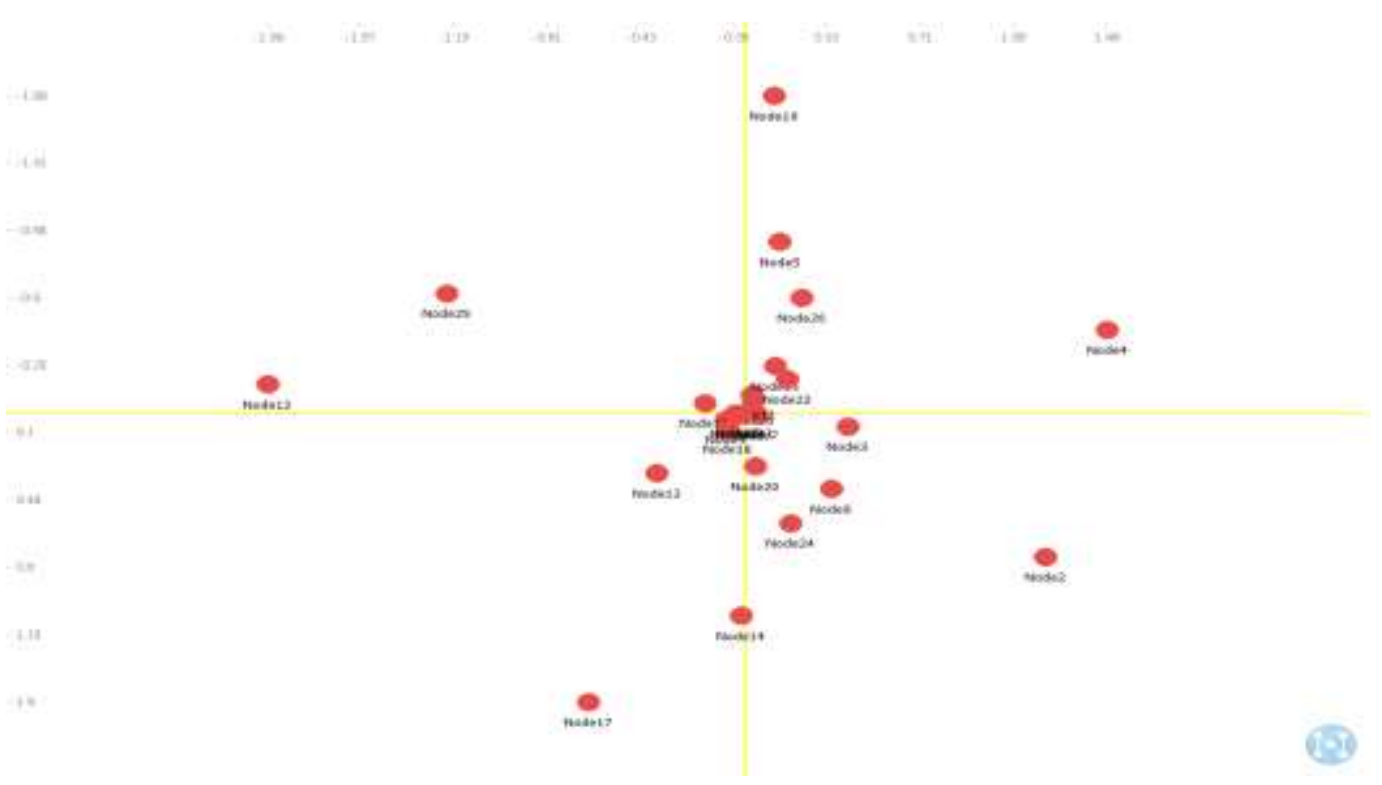

Fig. 30 Multidimensional scaling analysis results obtained by NetMiner

\section{CONCLUSION}

In the present study, I analyzed the degree of approaching children by their free will and found that they did not maintain that they had close peer relationships because they were close to and playing with their peers. The content of the case may be negative. Thus, the results of this study limit the qualitative aspects of interaction. However, the close distance between peers can be regarded as an indicator that the interest or influence of each other is high irrespective of the quality of the interaction.

Finally, regardless of the quality of the interaction, the degree of proximity can be an important indicator of interest or influence. Therefore, the results of this study are based on only the degree of proximity of interaction due to the limitation of quantitative collection data, but it can provide very important information about peer relations and provide important implications for the improvement of peer relations. 


\section{ACKNOWLEDGMENTS}

Funding for this paper was provided by Namseoul University year 2019.

\section{REFERENCES}

[1] S. Y. Kim, H. K. Park, Y. C. Choi, "Development of Peer Relationship Recognition and Analysis System by IoT-based Infant Precise Position Monitoring", Prowtech Co. Ltd \& Namseoul univ. \& Korea national univ. of edu. Research report, (2017).

[2] Kenneth H. Rubin, William M. Bukowski, Brett Laursen, "Handbook of Peer Interactions, Relationships, and Groups", Guilford Press, (2011).

[3] Allison M. Ryan, Gary W. Ladd, "Peer Relationships and Adjustment at School”, IAP, (2012).

[4] Jennifer A. Fredricks, Sandra D. Simpkins," Organized Out-of-School Activities: Setting for Peer Relationships", John Wiley \& Sons, (2013).

[5] BK Tripathy, J Anuradha, "Internet of Things (IoT): Technologies, Applications, Challenges and Solutions", CRC Press, (2017).

[6] Hiroto Yasuura, Chong-Min Kyung, Yongpan Liu, Youn-Long Lin, "Smart Sensors at the IoT Frontier", Springer, (2017).

[7] Myung-Soon Won, "The mediating effect of decision making ability on the relationship between courage and happiness in young children", Journal of the Korea Academia-Industrial cooperation Society 18.2, (2017), pp. 568-575.

[8] Jung-Gi Lee, Yeong-Seok Lee, "A Study on the Technology Development of User-based Home Automation Service", Journal of the Korea Academia-Industrial cooperation Society, 18.3, (2017), pp. 327-332.

[9] Mi-Young Kang, Ji-Seung Nam, "A Study on Smart Network Utilizing the Data Localization for the Internet of Things", Journal of the Korea Academia-Industrial cooperation Society 18.6(2017), pp. 336342.

[10] Seon-Keun Lee, "A Study on Pseudo-random Number Generator with Fixed Length Tap unrelated to the variable sensing nodes for IoT Environments", Journal of the Korea Academia-Industrial cooperation Society 19.2, (2018), pp. 676-682.

[11] Seon-Keun Lee, "A Study on Lightweight Block Cryptographic Algorithm Applicable to IoT Environment", Journal of the Korea Academia-Industrial cooperation Society 19.3, (2018), pp. 1-7.

[12] So-Yeon Min, Jae-Seung Lee, "Device Mutual Authentication and Key Management Techniques in a Smart Home Environment", Journal of the Korea Academia-Industrial cooperation Society 19.10, (2018), pp. 661-667.

[13] K. Kavitha Lakshmi, "Implementation of different Patterns for human Activities", International Journal of Urban Design for Ubiquitous Computing, 4.2, (2016), pp. 27-40.

[14] Ashish Bagwari, Jyotshana Kanti and Geetam Singh Tomar, "Multiple Antennas Based Sensing Technique", International Journal of Urban Design for Ubiquitous Computing 4.2, (2016), pp. 41-50.

[15] Peng Hai-yun, "Energy Consumption of Wireless Sensor Network Research Problem", International Journal of Internet of Things and Big Data 1.1, (2017), pp. 29-36.

[16] Weijie Kong, "Analyzing the Usage of Data Mining in Spatial Database", International Journal of Internet of Things and its Applications 1.1, (2017), pp. 1-12.

[17] Ranbeer Tyagi, "Fast Handoff in Wireless Communication Technology", International Journal of Wireless and Mobile Communication for Industrial Systems 4.1, (2017), pp. 43-56. 